\title{
Customer Response towards QR Codes Used in Marketing: An African Perspective
}

\author{
Randheer Kokku ${ }^{1}$ \\ ${ }^{1}$ College of Business Administration, King Saud University, Riyadh, Saudi Arabia \\ Correspondence: Kingdom of Saudi Arabia, Ministry of Higher Education, King Saud University (KSU), \\ College of Business Administration (CBA), P.O. Box 71115, Riyadh 11587, Saudi Arabia. E-mail: \\ rkokku@ksu.edu.sa
}

Received: March 18, 2021

Accepted: June 12, 2021

Online Published: July 20, 2021

doi:10.5539/ijbm.v16n9p15

URL: https://doi.org/10.5539/ijbm.v16n9p15

\begin{abstract}
Literature indicates QR code use in marketing is growing and needs attention. The objective of his research is to study QR codes use in marketing via accessibility of product information(PI), advertising(Ad), sales promotion(SP), billing and payment(BP) from African viewpoint. Correlation analysis paved way to factor analysis for data reduction. Both EFA and CFA were performed. Cronbach alpha and composite reliability were assessed for data reliability. Fit indices RMSEA, RFI, TLI and NFI were computed to check model fit. Regression slope was used for testing study hypothesis. Results found, customers use "product information, advertisements, sales promotion and billing \& payment through QR codes" has significant positive influence on perceived usefulness(PUM). Further, customers use of marketing QR codes proved perceived usefulness having significant positive influence on intention to use (IUM) in future course of time. "Tesco Homeplus" at global level succeeded in QR codes implementation for marketing activities is discussed and referred in the conclusions. Since respondents are positive towards perceived usefulness and intention to use QR codes, and the cost of QR technology and implementation is very less and affordable, the onus relies on marketing decision makers to adopt and promote QR codes in marketing aggressively for benefiting companies, customers and to further elevate African markets on mobile technological front.
\end{abstract}

Keywords: QR codes in African markets, QR codes in marketing, perceived usefulness of QR codes, intention to use QR codes, product information, advertising, sales promotion, billing and payment

\section{Introduction}

\subsection{The Need and Objective}

QR (quick response) code is a well-known technology to customers across several sectors like online and offline retailing, library services, fashion, fast food restaurants and others. QR code technology was invented during mid 1990's by Japanese company named Denso Wave. Since its invention was adopted well and used by industry in many areas including marketing (Chong, 2017). QR code technology adoption by customers is proportionate to smartphone ownership and internet users in a particular market. In African market the total smartphone ownership may reach 467 million by the end of year 2020 (Geraldine, 2017) and internet users were pegged at 453 million at the end of the year 2017 (SCANOVA, 2019). Scitechafrica (2019) brings about similar information saying African market is the fastest growing and second largest mobile market in the world. The body of a manuscript opens with an introduction that presents the specific problem under study and describes the research strategy. Because the introduction is clearly identified by its position in the manuscript, it does not carry a heading labeling it the introduction. Before writing the introduction, consider the following questions (Beck \& Sales, 2001, p. 100).

Mobi thinking (2012) discussed similar progress, adversely it also highlights that internet usage in some countries like Nigeria is not on par with other African nations due to domestic, technological and infrastructure reasons. Rao (2012) talks about QR technology to be one of the future innovations to be used with optimization in African markets. Further SCANOVA (2019) also highlighted that QR code technology penetrated into African markets for e-cash payments such as "Snapscan", "Youtap", "Zapper". Several banks in Africa launched independent applications with QR codes like First National Bank (FNB) in 2019 and Nedbank in 2018. 
Scitechafrica (2019) discussed how mobile payment technology with QR codes will be the next big change in African markets (Geraldine, 2017). In education sector "Bubbles technology" is using QR codes for spreading innovative learning, also "University of Cape Town" is using QR codes technology for library services. From marketing perspective, "Associated Media Publishing" is using QR codes technology for their products with an objective of making customer purchase easy. "Star FM, Zimbabwe" ran a campaign "Scan and win" in 2016 informing customer about their promotion offer. In 2017 "Great Ethiopian run" printed QR codes on participants t-shirts to promote the event. The above described QR code technology practices are examples of application and evidence of its success.

In view of the above it can be said that customer attitude towards existing technology, which is QR codes in this study have a significant effect on perceived usefulness (PU) and behavioral intention to use (BI) (Venkatesh \& Bala, 2008; Meydanoglu, Cilingirturk, Bohm, \& Klein 2018). The future of QR code application in African markets is definitely a happening technology. The objective of this research is to explore African customer behavior of QR codes technology in marketing activities PI (product information), AD (advertisement) SP (sales promotion) and BP (billing and payment) in relation to time tested consistent constructs; perceived usefulness(PU) and intention to use (IU) from technology adoption models TRA, TAM and UTAUT.

There were attempts in the past in this direction, but covered isolated topics of marketing in relation to QR codes, present study covered use of QR codes among four important activities of marketing, this is the major contribution of this study. This research is sequenced starting with introduction on QR codes in African markets, theoretical discussion on technology adoption models covering constructs PU an IU, followed by QR codes implementation in marketing. Literature showcases review of four independent variables PI (product information), AD (advertisement) SP (sales promotion) and BP (billing and payment). Two dependent variables PU, IU and hypothesis. Method details sampling, questionnaire and data collection. Discussion on results involves data reduction, reliability, fit indices and regression beta. Implications and conclusions are drawn based on results and successful industry practices. At the end extension of present research is given.

\subsection{Theoritical Background}

In the academic research there is sufficient focus on new technology acceptance theories/models. Liebenberg, Benade and Ellis, (2018) tested Unified Theory of Acceptance and Use of Technology (UTAUT) in Africa. Elue and Nakakawa (2018) and Liebenberg et al. (2018) in their research discussed successful technology acceptance models such as Technology Acceptance Model (TAM) and Theory of Planned Behaviour (TPB). There are also studies which investigated QR code technology and its acceptance among customers. A large number of papers already provided evidence on QR code acceptance using above discussed models and also theory of Reasoned Action(TRA) and other related theories.

Technology adoption models and QR -Technology adoption theories have inclusion of individual attitude perspectives in addition to technology adoption. Perceived usefulness of technology and intention to use are the two-common individual attitudinal constructs found. According to Theory of Reasoned Action (TRA) (Ajzen \& Fishbein, 1980), individuals possess attitude (A) towards technology as; easy to use, is useful, less risky and also certain intentions like will use it, will advise others to use like QR codes. This theory also highlights what motivates individuals leading to certain actions, like a set of information is relevant, useful, appealing, creative, attractive; this may ignite purchase, positive word of mouth. This theory was advanced by Theory of Planned Behavior (TPB) framework (Ajzen, 1991), where perceived behavior is horizontal to self-efficacy of using a technology such as QR codes and the behavior of an individual is affected and controlled by factors of beliefs. It also explains individuals' expectations derived from beliefs and attitudes to that of outcomes which are net difference between behavioral intention (BI) (Meydanoglu et al., 2018) and actual behavior (AB) (Lombardi, Carfora, Cicia, Giudice, Lombardi, \& Panico, 2017). Technology Acceptance Model(TAM) (Davis, 1989) had narrowed to understand an individual behavior in using and adopting technology. This model theorizes that under the influence of external variables (EV), an individual categorizes beliefs into perceived usefulness (PU) and perceived ease of use (PEOU) of technology like QR codes (Higgins et al., 2014); these beliefs help his attitude (A) in using the technology paving way to behavioral outcome of intention (BI) to use and actual use. After a decade, it was simplified to be known as TAM1 (Venkatesh \& Davis,1996) with the elimination of attitude (A). External variables were still antecedent of PU and PEOU. Independent variable PU moderated by PEOU effected BI which further influenced actual system use.

Venkatesh and Davis (2000) upgraded the model with major changes known as TAM2. Perceived usefulness (PU) still remains the antecedent of behavioral intention (BI) and PEOU holds similar relationship. One set of independent variables from social influence; image and subjective norm (SN) effect PU, also SN effecting BI 
directly moderated by voluntariness. Another set of independent variables based on cognitive process; result demonstrability directly affects PU and job relevance moderated by output quality. A study done by Shin, Jung, and Chang (2012) found that perceived quality of QR codes positively influences perceived usefulness (PU). Another cognitive variable "experience" moderates SN while it effects PU and BI. TAM 3 (Venkatesh \& Bala, 2008) had replicated TAM2, with addition of independent variables effecting PEOU. Independent variables were categories into "Anchor (means existing attitude towards technology) variables; computer self-efficacy, perceptions of external control, computer anxiety, computer playfulness" and "Adjustment (means cognitive experience from new technology) variables; perceived enjoyment and objective usability". Additionally, cognitive variable "experience" moderates anchor and adjustment variables effecting PEOU; and PEOU effecting PU and BI. Venkatesh, Morris, Davis, and Davis (2003) proposed a new model named "Unified theory of acceptance and use of technology" (UTAUT) with an objective of giving more weightage to acceptance and use of technology by users. They considered four independent variables viz, performance expectancy, effort expectancy, social influence and facilitating conditions affecting BI and further BI and facilitating conditions affecting user behavior. Jung, et al. (2012) in their study had found that social influence has positive effect on intention to use advertising QR codes. Extension to UTAUT; UTAUT2 was theorized by Venkatesh, Thong, and $\mathrm{Xu}$ (2012). UTAUT 2 replicates UTAUT, but adds three additional independent variables "hedonic motivations, price value and habit" affecting BI, with habit directly affecting use behavior. Davis (1989) had discussed the role of perceived usefulness (PU) and perceived ease of use (PEOU) among new communication technologies in marketing. He found that PU and PEOU have effect on user behaviour.

\subsection{Literature Review}

QR and Marketing - In their study Lombardi et al. (2017) had referred above mentioned theories and numerous related studies to investigate attitude change through technology/information processing accessed from QR codes, hence it would be more significant to explore less probed areas like QR code technology application into marketing practice and develop a framework of marketing QR codes (see figure 1). Okazaki, Angeles, Prokriti and Kirk (2017) had given a supporting view stating that "QR codes are among the most understudied research topics in advertising and marketing", hence this study addresses this gap. Similarly, academic research on QR codes application in marketing and African context is very less, only exception being mobile payments. Okazaki, Hirose and Li (2011) in their study had discussed QR code itself as a marketing tool (Chong, 2017), similarly Asare and Asare (2015) had discussed the effective role of QR codes in marketing. Singh and Bamoriya (2013) had discussed the benefits of QR code affecting the marketing investment indicating high customer acceptance. QR code technology had been adopted well by customers with thousand-fold increase was reported across many studies (Singh \& Bamoriya, 2013). Gonul, Qiu and Zhou (2016) found use of QR codes are going to increase in general. Humbani and Wiese (2018) had revealed, QR codes for payments of different kinds of transactions were used by 2.1 million customers in South Africa as of 2014, highest in Africa. Besides, there are other markets such as Kenya, Nigeria and so on. Adversely, Okazaki et al. (2017) in their study reported that because of low consumer acceptance QR codes are dying.

Marketers started focusing on using QR technology in four customer interfacing activities viz; PI (product information) accessed via clicking AD (advertisement) which further stimulated by sales promotion (SP) leading to purchase, billing and payment (BP). This study advocates creation of product knowledge and awareness among the target group through information. Findings from Okazaki et al. (2011) reveal that QR codes are popular among consumers in accessing PI, it gained attention, when QR codes were advertised across plethora of media sources such as flyers, newspapers, magazines, metro stations, bus bays, billboards. QR code lead the customer directly to PI just by a scan or a click. It gives opportunity for the customer to look at the details of product specifications, cross comparison with competing products, price details, product demo, product trial details, terms and conditions of purchase.

The success of PI depends on its relevance and perceived usefulness to the customers (Shin et al., 2012). More the customers feel information is useful; they will adopt QR codes for receiving information (Higgins, Wolf \& Wolf, 2014), concurrent to this the affective attitude generated through information leads to liking, preference and conviction through AD QR codes (Singh \& Bamoriya, 2013; Narang, Jain, \& Roy, 2012; Okazaki et al., 2011). In their research paper Lavidge and Steiner (1961) had given three functions of advertising firstly advertising creates awareness and spreads knowledge, secondly customers will develop liking and start preference with a favorable attitude and thirdly customers will confine their thought for definite purchase, similarly advertising QR codes do exhibit these three functions (Jung, Somerstein, \& Kwon, 2012). Additionally, SP QR codes target and attract specific group of customers, these customer groups perceive specific message as appealing and useful; and their conviction attitude is driven by attractiveness when advertising is spiced up with 
sales promotion offers (Singh \& Bamoriya, 2013). The conative action leads to BP sent via QR code; customer's acceptance of code will lead to payment gate to finish the transaction. The transaction is financial by nature; hence security of the transaction is viewed most important to reduce the customer risk (Cabanillas, Luna, \& Rios, 2015; Kim \& Yoon, 2014). Humbani and Wiese (2018) in their study had discussed the consumer issues with regards to insecurity of payments through mobile phone, they discussed hacking can be a reason of consumer feeling of risk. Alternately Lubua and Pretorius, (2018) in their study had found that when the financial transaction is error free, consumers will feel useful, adopt and use the technology in future course of time.

\subsection{Hypotheses Framing}

Product information (PI) - QR code gives customers opportunity to access information which he feels relevant to his utilitarian and hedonic needs (Lombardi et al, 2017). Kim and Yoon (2014) in their study discussed that customer expects product information to be the key factors when using QR codes. Customer experience of technology drives him to belief usefulness and further use it (Venkatesh \& Davis, 2000), a similar argument was established by Higgins et al. (2014) for QR codes use related to product information. Narang et al. (2012) were critical of ELM, they highlighted that access of QR codes gives consumers sufficient product information leading to usefulness of such information. The conative behavioral framework of customer is pre-fixed on certain expectations, customer access of QR codes for product information should match his expectations to make a reasoned judgement on perceived usefulness of the information and further developing an intention to keep using the QR codes in future course of time, similarly Ajzen and Fishbein (1980) also said usefulness leads to attitude (A) towards using. Higgins et al. (2014) in their study had found that consumers when scan QR codes get information about product, upon feeling useful they use QR codes and adopt them (Shin et al., 2012; Jung, et al., 2012).

\section{H1: Product information QR codes positively influences perceived usefulness}

Advertising (AD) - The Ad codes lead customer to the message (Gonul, Qiu \& Zhou, 2016). Kim and Yoon (2014) in their study opined that people exposed to ad's though QR codes have good chances of becoming potential sales leads. Advertising as a stimulant can be used for measuring consumer intention (Lavidge \& Steiner, 1961). The successful effectiveness of the message depends on how well it is perceived to be useful. The usefulness of the advertising has a role to play. Usefulness of message needs balancing approach between rationality; focusing on logical side of human thought process and emotional side touching upon feelings and likes. Venkatesh et al. (2012) in their study reveal that hedonic motives have influence on behavioral intention to use (BI). The reader of the message should perceive the message to be useful and beneficial. The perception of usefulness by customers when exposed to technology leads to acceptance (Venkatesh \& Davis,1996). Singh and Bamoriya (2013) in their study had discussed the work of (Ann, 2012) informing that QR advertisements should be creatively appealing to invoke the customer to either sign-up or involve in the message. Okazaki et al. (2017) had argued that advertising should balance complexity for consumers to accept QR codes.

\section{$\mathrm{H} 2$ : Advertising QR codes positively influences perceived usefulness}

Sales Promotion (SP) - Advertisements created with an objective of informing or for awareness building are less attractive for sales generation. When the objective is to make customer involve in sales action, attractive sales promotion QR codes should be added to be perceived useful by the customers. Ajzen (1991) in his study reveals beliefs of individuals affect one's own behavior, similarly sales promotion accessed through QR codes makes consumer feel smart buying in terms of savings and free gaining. Singh and Bamoriya (2013) had suggested that incentive-based promotion leads to increased attractiveness and effectiveness of advertising. In other terms usefulness of sales promotion help customers in finalizing their decision on QR codes use.

\section{$\mathrm{H} 3$ : Sales promotion $\mathrm{QR}$ codes positively influences perceived usefulness}

Billing and payment (BP) - Performance expectancy is given higher preference by customers while using technology to perceive it to be more useful (Venkatesh et al., 2003). Performance in the form of error free bills and fully secured payments are preferred by customers for finishing the transaction. Cabanillas et al. (2015) in their study had dealt with user's perception about security of transaction. They opined that safety and security mechanisms should be put in place so as the user feels low on risk leading to confidence building. Adversely Singh and Bamoriya (2013) highlighted the possibility of bogus codes hacking into personal information. Upon finalizing the cart, customer clicks the code to access the bill and complete the payment process. Customer will perceive the billing and payment to be useful when the process is secured without any risk (Kim \& Yoon, 2014; Elue \& Nakakawa, 2018). Customers are highly sensitive towards risking with financial transaction hence its adoptability. Lubua and Pretorius, (2018) had confirmed that assurance of financial transaction without risk will allow customers to use the technology on a continuous basis. 
H4: Billing and payment QR codes positively influences perceived usefulness

H5: Perceived usefulness of Marketing QR codes positively influences Intention to use

\section{Method}

In marketing QR code use is in early growth stage. Both companies and customers have adopted the technology but lag motive to put into marketing activities widely. Hence research had not focused on integrated approach on QR and marketing

\subsection{Items}

Items were picked from various independent research works. The process followed with item generation, scale measurement and evaluation presented by Hinkin (1995). With a thorough search of literature from the available resource's items were finalized for the scale. Scale was categorised into six sections via product information, advertising, sales promotion and billing/payment, perceived usefulness and intention to use. A total of 35 items were adapted and modified for independent and dependent variables from (Kim \& Yoon, 2014; Singh \& Bamoriya, 2013; Narang et al., 2012; Okazaki et al., 2011; Venkatesh \& Bala, 2008).

\subsection{Validity}

Face validity was done using a group of three experts (business college professors) to examine the initial questionnaire. Expert group suggested deletion of 7 items categorized as redundant, confusing and double barrel which are bolden. The study finalized 28 items (refer Appendix A). Final questionnaire used seven-point Likert scale, where 7 indicated "strongly accept" and 1 "strongly reject". Respondents were asked to read the statements and give their opinion wether they accept or reject them on an 1 to 7 adjective "strongly".

\subsection{Sample and Data Collection}

Data collection was done with the help of students and faculty members from Africa in King Saud University. They provided reference e-mails of family members, African friends, and any known African persons and were assured email id's will be kept confidential and used only for this research; will not be used for other purposes. Questionnaire was mailed initially to 1040 elements with a response rate was $18.46 \%$, which was low in comparison to number of statements in the questionnaire. In the second attempt questionnaire was emailed to those who did not respond. 127 responded, response rate increased to $30.67 \%$ with a total of 319 questionnaires qualified and were usable for data analysis. (see table1). First attempt data collection was done between October and December 2019. Second attempt data collection was done from February to April, 2020. For data analysis IBM SPSS 25.0 Microsoft windows version was used. Questionnaires which were 100\% complete were considered. Coding of questionnaires was done before analysis of data. Manually data was checked and feed into SPSS. Correlation between item-constructs and reliability, validity was assessed in the measurement model. Hypothesis testing and fit indices were assessed in structural model. Guidelines given by (Ramayah, Cheah, Chuah, Ting \& Memon, 2016) and Verma (2013) were followed for analysis.

Table 1. Sample elements

\begin{tabular}{cccc}
\hline $\begin{array}{c}\text { Nationals by } \\
\text { Country }\end{array}$ & $\begin{array}{c}\text { Number of E-mails } \\
\text { collected }\end{array}$ & $\begin{array}{c}\text { Number of responses in the first } \\
\text { attempt }\end{array}$ & $\begin{array}{c}\text { Number of responses in the first attempt (+) } \\
\text { second attempt }\end{array}$ \\
\hline Nigeria & 227 & 34 & $34+30$ \\
Sudan & 388 & 56 & $56+38$ \\
South Africa & 205 & 58 & $58+32$ \\
Egypt & 220 & 44 & $44+27$ \\
Total & 1040 & 192 & 319 \\
\hline
\end{tabular}

\section{Results}

\subsection{Factor Analysis}

Total responses were divided into two; 160 responses were used for performing EFA and 159 used for CFA. A section of research community supports division of sample responses for performing EFA and CFA independently giving the reason that EFA is used for identifying constructs from items whereas CFA is for validity/reliability and to validate the model fit. To check the initial relationship, inter item correlation was 
assessed using spearmen correlation (refer table 2). The correlation values ranged between -.544 and .941 assumed to be on higher side; hence this gave the study model a good chance for factor analysis. As discussed by Podsakoff, MacKenzie, Lee and Podsakoff (2003) EFA (exploratory factor analysis) with PCA (principle component analysis) was performed. Since the items taken and modified for each construct were from different studies a prior validity was lacking, hence EFA was performed. Component matrix resulted in 11 components (refer table 3). In the component matrix (refer table 5), cross correlations between items and components are mapped. Loadings more than .4 were considered satisfactory, none of the items loaded less than this, hence all the items were retained for further analysis. In the total variance explanation, initial eigenvalues scoring more than 1 are considered as components. This analysis had identified six components explaining a cumulative variance of $93.693 \%$, with the first component explaining $31.161 \%$, which falls within less than $50 \%$ criteria, hence common method bias does not affect the study data (Venkatesh \& Bala, 2008). All the values of communality $\left(\mathrm{h}^{2}\right)$ range between 0 and 1 , though they are not close to 1 , but are able to explain variance of each individual item (refer table 4). The total variance explained by $\mathrm{h}^{2}$ which is 10.24 is equal to the sum of engine values of six components 10.244. To support the appropriateness of factor analysis application, correlation supported by Bartlett test of sphericity found significant results with chi-square value of 9,407 at $p=0.01$. Also, KMO with 0.91 indicated higher sampling adequacy. To further check whether constructs represented satisfactorily by measured variables and check the model fitness, CFA was conducted by setting six factors in which all the items were expected to be fitted. In relation to this assumption, CFA results are shown in the table 7. Discriminant validity was assessed by standardized loadings (Hair, Marko, Lucas \& Volker, 2014) for inter factor/construct-items which were greater than .70 and all cross loadings were less than .30 (Venkatesh \& Bala, 2008). Inter-correlations are used to know the convergent validity(refer table 6). Observations of the values reveal that convergent validity among the factors is more than .9 which is on higher side. Whereas inter-correlations among factors range between .118 to .515 , provides evidence of construct validity and operationalizing the theoretical underpinnings. Some argue that these correlations cut-off is .85 , but some say that higher correlation results in redundancy and inappropriate selection and measurement. The reliability of the factors was measured by Cronbach alpha (Cronbach, 1971) resulting in more than .7 for all the factors (refer table 6). The study felt there was a need to check for further internal consistency and improvement was initiated in the next stage below.

Table 2 Pearson Correlation r values

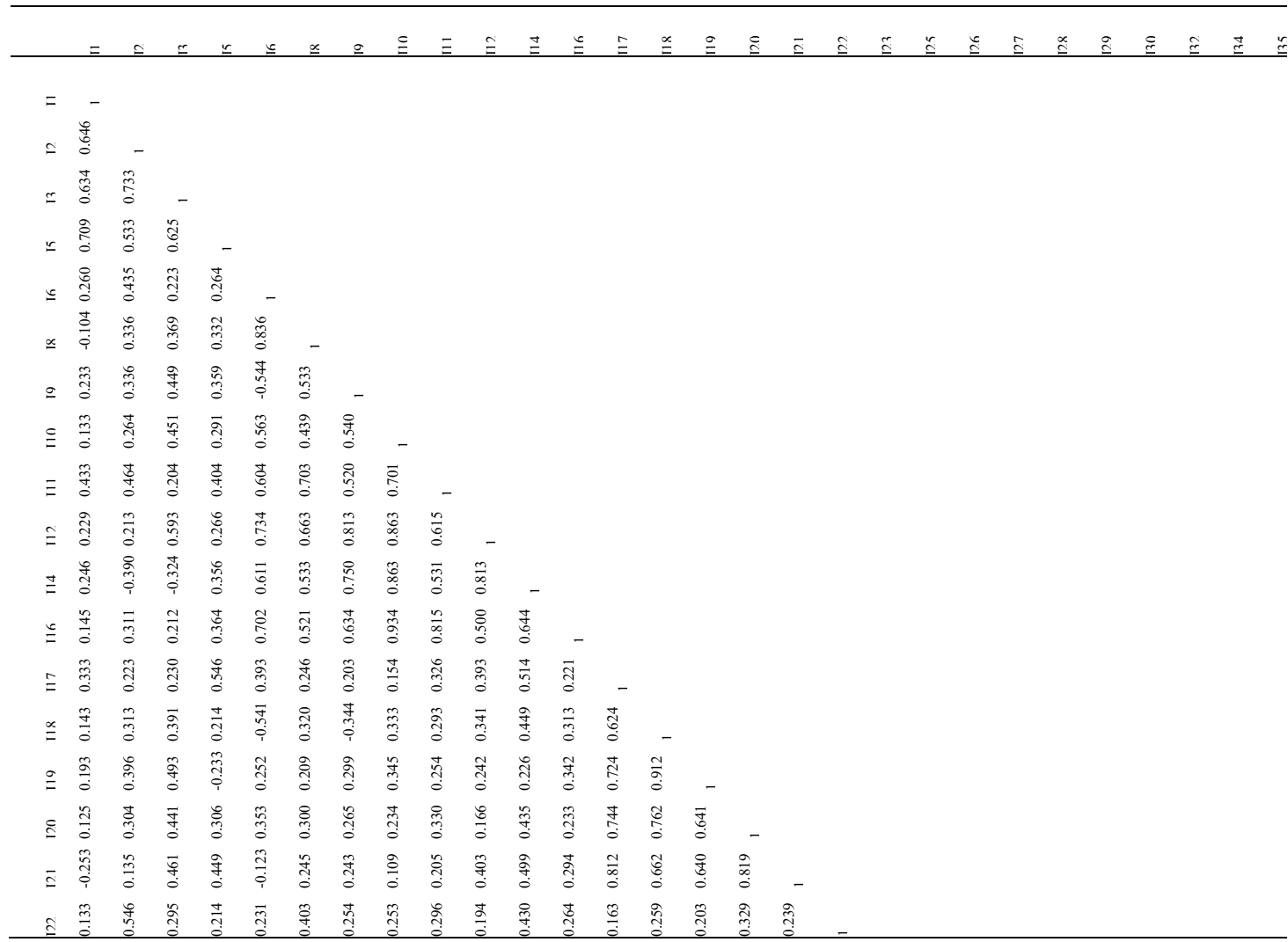




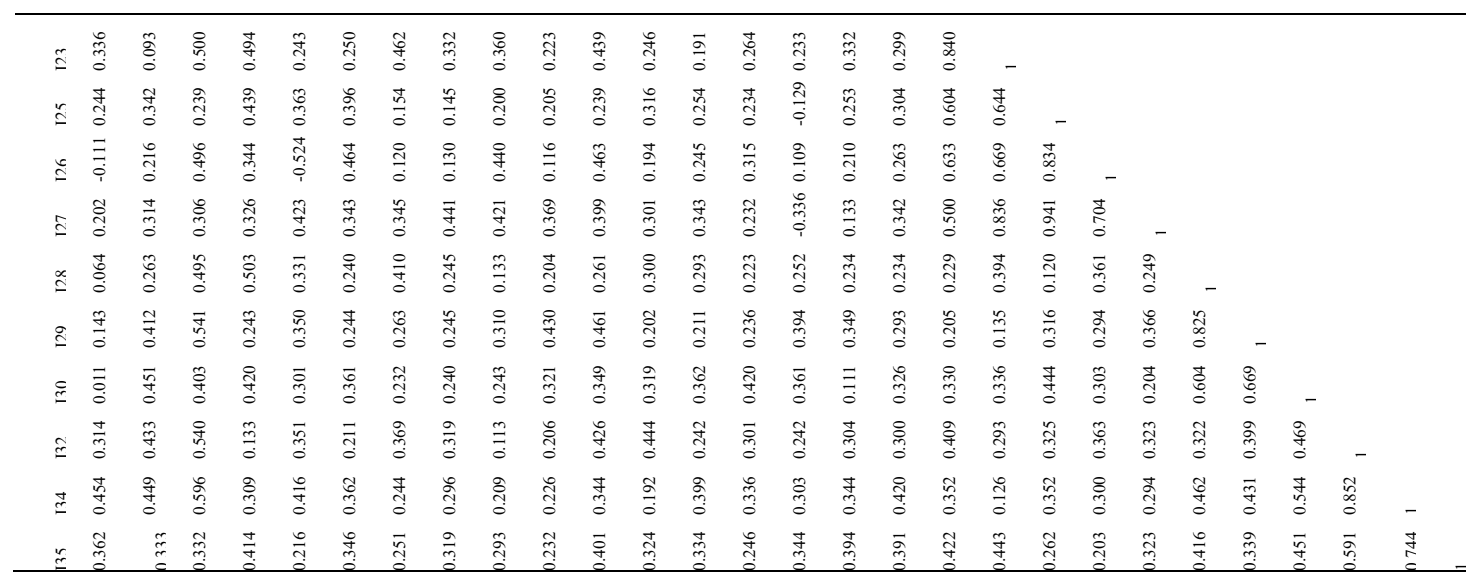

Table 3. Total variance explained

\begin{tabular}{|c|c|c|c|c|c|c|}
\hline \multirow[t]{2}{*}{ Components } & \multicolumn{3}{|c|}{ Initial Eigenvalues } & \multicolumn{3}{|c|}{ Extraction Sums of Squared Loadings } \\
\hline & Total & $\begin{array}{ll}\% \% & \text { of } \\
\text { Variance } & \end{array}$ & Cumulative \% & Total & $\%$ of Variance & Cumulative $\%$ \\
\hline 1 & 3.392 & 31.161 & 31.161 & 3.392 & 31.161 & 31.161 \\
\hline 2 & 1.608 & 14.733 & 45.894 & 1.608 & 14.733 & 45.894 \\
\hline 3 & 1.551 & 14.131 & 60.025 & 1.551 & 14.131 & 60.025 \\
\hline 4 & 1.5 & 13.653 & 73.678 & 1.5 & 13.653 & 73.678 \\
\hline 5 & 1.129 & 10.295 & 83.973 & 1.129 & 10.295 & 83.973 \\
\hline 6 & 1.064 & 9.72 & 93.693 & 1.064 & 9.72 & 93.693 \\
\hline 7 & 0.166 & 1.5993 & 95.2923 & Total $=10.244$ & & \\
\hline 8 & 0.167 & 1.5971 & 96.8894 & & & \\
\hline 9 & 0.129 & 1.174 & 98.0634 & & & \\
\hline 10 & 0.112 & 1.0233 & 99.0867 & & & \\
\hline 11 & 0.182 & 0.9123 & 100.000 & & & \\
\hline
\end{tabular}

Table 4. Communalities

\begin{tabular}{lllllllll}
\hline Item & Initial & Extracted & Item & Initial & Extracted & Item & Initial & Extracted \\
\hline I1 & 1 & 0.462394 & I12 & 1 & 0.631876 & I23 & 1 & 0.341452 \\
I2 & 1 & 0.473193 & I14 & 1 & 0.334887 & I25 & 1 & 0.352175 \\
I3 & 1 & 0.534543 & I16 & 1 & 0.380118 & I26 & 1 & 0.436462 \\
I4 & 1 & 0.475362 & I17 & 1 & 0.349956 & I27 & 1 & 0.455994 \\
I6 & 1 & 0.401372 & I18 & 1 & 0.28993 & I28 & 1 & 0.293676 \\
I8 & 1 & 0.297492 & I19 & 1 & 0.194896 & I29 & 1 & 0.419302 \\
I9 & 1 & 0.508248 & I20 & 1 & 0.74438 & I30 & 1 & 0.289037 \\
I10 & 1 & 0.314965 & I21 & 1 & 0.472665 & I32 & 1 & 0.067924 \\
I11 & 1 & 0.277362 & I22 & 1 & 0.258392 & I34 & 1 & 0.116826 \\
& & & & & & I35 & 1 & 0.070976 \\
& & & & & & Total & & 10.24586 \\
\hline
\end{tabular}

\subsection{Reliability and Fit Indices}

Literature suggests that Cronbach alpha at times estimates the reliability either low or high. Since this study involves multidimensional aspects there is sufficient probability that alpha may be lower bound that it may underestimate the reliability of the scale. Hence with the help of composite reliability much more accurate reliability scores were generated with the heterogeneous scale of the study (Robert \& Yeolib, 2013). Suggestions from other research studies as Ramayah et al. (2016) lead this study to compute the composite reliability(CR). Upon comparison of Cronbach alpha values with composite reliability, the later values are higher than the prior (See table 7). Additionally, average variance extracted(AVE) advised by Fornell and Larcker (1981) was assessed. This study followed Hair, Black, Babin, and Anderson (2009) to measure multidimensional construct scale fitness by relative likelihood ratio which resulted as 2.84. "Root Mean Square Error of Approximation" (RMSEA) 
resulted as 0.032 and other two fit indices "Relative Fit Index" (RFI), "Tucker-Lewis Index" (TLI) and "Normed Fit Index" (NFI) were $0.74,0.93$ and 0.80 respectively.

Table 5. Component matrix

\begin{tabular}{|c|c|c|c|c|c|c|c|c|c|c|c|}
\hline & 1 & 2 & 3 & 4 & 5 & 6 & 7 & 8 & 9 & 10 & 11 \\
\hline I1 & 0.646 & 0.122 & 0.125 & 0.099 & 0.012 & 0.068 & 0.048 & 0.005 & 0.099 & 0.006 & 0.029 \\
\hline $\mathrm{I} 2$ & 0.644 & 0.102 & 0.028 & 0.168 & 0.111 & 0.082 & 0.069 & 0.082 & 0.054 & 0.009 & 0.018 \\
\hline I3 & 0.709 & 0.025 & 0.069 & 0.102 & 0.126 & 0.014 & 0.026 & 0.096 & 0.002 & 0.055 & 0.046 \\
\hline I5 & 0.662 & 0.086 & 0.089 & 0.059 & 0.044 & 0.128 & 0.045 & 0.098 & 0.028 & 0.005 & 0.004 \\
\hline I6 & 0.613 & 0.016 & 0.051 & 0.101 & 0.068 & 0.089 & 0.14 & 0.009 & 0.002 & 0.022 & 0.01 \\
\hline I8 & 0.288 & 0.464 & 0.104 & 0.104 & 0.104 & 0.002 & 0.12 & 0.101 & 0.108 & 0.092 & 0.009 \\
\hline I9 & 0.228 & 0.662 & 0.092 & 0.066 & 0.024 & 0.068 & 0.012 & 0.068 & 0.015 & 0.158 & 0.082 \\
\hline I10 & 0.122 & 0.518 & 0.024 & 0.156 & 0.011 & 0.082 & 0.15 & 0.062 & 0.021 & 0.018 & 0.056 \\
\hline I11 & 0.129 & 0.506 & 0.012 & 0.064 & 0.002 & 0.021 & 0.008 & 0.024 & 0.005 & 0.1 & 0.008 \\
\hline I12 & 0.346 & 0.642 & 0.22 & 0.186 & 0.098 & 0.086 & 0.208 & 0.158 & 0.026 & 0.092 & 0.004 \\
\hline I14 & 0.185 & 0.501 & 0.101 & 0.114 & 0.141 & 0.02 & 0.084 & 0.088 & 0.008 & 0.081 & 0.089 \\
\hline I16 & 0.222 & 0.018 & 0.562 & 0.009 & 0.052 & 0.109 & 0.099 & 0.005 & 0.008 & 0.002 & 0.006 \\
\hline $\mathrm{I} 17$ & 0.108 & 0.096 & 0.544 & 0.006 & 0.152 & 0.1 & 0.005 & 0.028 & 0.02 & 0.066 & 0.085 \\
\hline I18 & 0.292 & 0.108 & 0.416 & 0.089 & 0.1 & 0.045 & 0.048 & 0.109 & 0.105 & 0.108 & 0.009 \\
\hline I19 & 0.025 & 0.085 & 0.414 & 0.014 & 0.081 & 0.008 & 0.054 & 0.008 & 0.096 & 0.004 & 0.02 \\
\hline $\mathrm{I} 20$ & 0.352 & 0.086 & 0.594 & 0.194 & 0.088 & 0.05 & 0.002 & 0.022 & 0.06 & 0.002 & 0.009 \\
\hline $\mathrm{I} 21$ & 0.282 & 0.098 & 0.579 & 0.279 & 0.162 & 0.106 & 0.054 & 0.005 & 0.1 & 0.005 & 0.189 \\
\hline $\mathrm{I} 22$ & 0.226 & 0.142 & 0.096 & 0.416 & 0.028 & 0.064 & 0.02 & 0.22 & 0.04 & 0.016 & 0.068 \\
\hline $\mathrm{I} 23$ & 0.224 & 0.016 & 0.106 & 0.528 & 0.028 & 0.018 & 0.045 & 0.081 & 0.001 & 0.069 & 0.099 \\
\hline $\mathrm{I} 25$ & 0.211 & 0.118 & 0.095 & 0.521 & 0.121 & 0.04 & 0.11 & 0.085 & 0.008 & 0.008 & 0.061 \\
\hline I26 & 0.102 & 0.162 & 0.081 & 0.615 & 0.115 & 0.058 & 0.008 & 0.045 & 0.21 & 0.12 & 0.111 \\
\hline $\mathrm{I} 27$ & 0.268 & 0.012 & 0.108 & 0.451 & 0.151 & 0.131 & 0.022 & 0.04 & 0.008 & 0.001 & 0.119 \\
\hline I28 & 0.103 & 0.051 & 0.24 & 0.088 & 0.461 & 0.161 & 0.069 & 0.019 & 0.018 & 0.006 & 0.106 \\
\hline I29 & 0.311 & 0.132 & 0.096 & 0.209 & 0.502 & 0.102 & 0.084 & 0.006 & 0.009 & 0.026 & 0.008 \\
\hline $\mathrm{I} 30$ & 0.014 & 0.089 & 0.022 & 0.118 & 0.516 & 0.216 & 0.051 & 0.019 & 0.002 & 0.022 & 0.101 \\
\hline $\mathrm{I} 32$ & 0.121 & 0.124 & 0.012 & 0.041 & 0.019 & 0.489 & 0.04 & 0.044 & 0.028 & 0.008 & 0.109 \\
\hline $\mathrm{I} 34$ & 0.218 & 0.004 & 0.162 & 0.18 & 0.029 & 0.599 & 0.004 & 0.009 & 0.081 & 0.061 & 0.166 \\
\hline $\mathrm{I} 35$ & 0.142 & 0.084 & 0.062 & 0.082 & 0.182 & 0.508 & 0.008 & 0.086 & 0.12 & 0.098 & 0.108 \\
\hline
\end{tabular}

Table 6. Inter-correlations among factors

\begin{tabular}{|c|c|c|c|c|c|c|c|}
\hline Constructs & $\mathrm{PI} / \mathrm{QR}$ & $\mathrm{AD} / \mathrm{QR}$ & $\mathrm{SP} / \mathrm{QR}$ & $\mathrm{BP} / \mathrm{QR}$ & PUM/QR & IUM/QR & $\begin{array}{l}\text { Cronbach } \\
\text { Alpha }\end{array}$ \\
\hline $\mathrm{PI} / \mathrm{QR}$ & .915 & & & & & & 0.86 \\
\hline $\mathrm{AD} / \mathrm{QR}$ & .488 & .937 & & & & & 0.80 \\
\hline $\mathrm{SP} / \mathrm{QR}$ & .357 & .324 & .961 & & & & 0.83 \\
\hline $\mathrm{BP} / \mathrm{QR}$ & .420 & .321 & .118 & .901 & & & 0.74 \\
\hline PUM/QR & .208 & .450 & .427 & .437 & .944 & & 0.79 \\
\hline IUM/QR & .515 & .411 & .386 & .394 & .364 & .938 & 0.81 \\
\hline
\end{tabular}


Table 7. Composite reliability values and average variance

\begin{tabular}{|c|c|c|c|c|c|c|}
\hline $\begin{array}{l}\text { Constructs } \\
\text { Item(I) }\end{array}$ & $\begin{array}{c}\mathrm{PI} / \mathrm{QR} \\
0.888^{* * *} \\
0.669^{* * * *}\end{array}$ & $\begin{array}{c}\mathrm{AD} / \mathrm{QR} \\
0.951 * * * \\
0.710^{* * * *}\end{array}$ & $\begin{array}{c}\mathrm{SP} / \mathrm{QR} \\
0.923 * * * \\
0.698 * * * *\end{array}$ & $\begin{array}{c}\mathrm{BP} / \mathrm{QR} \\
0.918^{* * *} \\
0.693 * * * *\end{array}$ & $\begin{array}{l}\mathrm{PUM} / \mathrm{QR} \\
0.882^{* * *} \\
0.715 * * * *\end{array}$ & $\begin{array}{l}\text { IUM/QR } \\
0.860^{* * *} \\
0.673 * * * *\end{array}$ \\
\hline I1 & $\begin{array}{l}0.790^{*} \\
14.208^{* *}\end{array}$ & & & & & \\
\hline I2 & $\begin{array}{l}0.846^{*} \\
11.404 * *\end{array}$ & & & & & \\
\hline I3 & $\begin{array}{l}0.925^{*} \\
10.058^{* *}\end{array}$ & & & & & \\
\hline I5 & $\begin{array}{l}0.757^{*} \\
18.220^{* *}\end{array}$ & & & & & \\
\hline I6 & $\begin{array}{l}0.911 * \\
15.647 * *\end{array}$ & & & & & \\
\hline I8 & & $\begin{array}{l}0.947^{*} \\
10.446^{* *}\end{array}$ & & & & \\
\hline I9 & & $\begin{array}{l}0.718^{*} \\
13.477^{* *}\end{array}$ & & & & \\
\hline I10 & & $\begin{array}{l}0.770^{*} \\
16.547^{* *}\end{array}$ & & & & \\
\hline I1 1 & & $\begin{array}{l}0.843 * \\
19.007 * *\end{array}$ & & & & \\
\hline I12 & & $\begin{array}{l}0.898^{*} \\
20.640^{* *}\end{array}$ & & & & \\
\hline I14 & & $\begin{array}{l}0.716^{*} \\
19.443^{* *}\end{array}$ & & & & \\
\hline I16 & & & $\begin{array}{l}0.907 * \\
18.004 * *\end{array}$ & & & \\
\hline I17 & & & $\begin{array}{l}0.806^{*} \\
11.078^{* *}\end{array}$ & & & \\
\hline I18 & & & $\begin{array}{l}0.804^{*} \\
15.439 * *\end{array}$ & & & \\
\hline I19 & & & $\begin{array}{l}0.927^{*} \\
21.488^{* *}\end{array}$ & & & \\
\hline I20 & & & $\begin{array}{l}0.800^{*} \\
14.419^{* *}\end{array}$ & & & \\
\hline I21 & & & $\begin{array}{l}0.861^{*} \\
16.027^{* *}\end{array}$ & & & \\
\hline $\mathrm{I} 22$ & & & & $\begin{array}{l}0.900 * \\
16.018 * *\end{array}$ & & \\
\hline $\mathrm{I} 23$ & & & & $\begin{array}{l}0.820^{*} \\
10.275^{* *}\end{array}$ & & \\
\hline $\mathrm{I} 25$ & & & & $\begin{array}{l}0.808^{*} \\
8.550^{* *}\end{array}$ & & \\
\hline I26 & & & & $\begin{array}{l}0.918^{*} \\
14.773 * *\end{array}$ & & \\
\hline I27 & & & & $\begin{array}{l}0.701^{*} \\
18.617^{* *}\end{array}$ & & \\
\hline $\mathrm{I} 28$ & & & & & $\begin{array}{l}0.817^{*} \\
22.418^{* *}\end{array}$ & \\
\hline I29 & & & & & $\begin{array}{l}0.805^{*} \\
10.554^{* *}\end{array}$ & \\
\hline $\mathrm{I} 30$ & & & & & $\begin{array}{l}0.911^{*} \\
14.071^{* *}\end{array}$ & \\
\hline $\mathrm{I} 32$ & & & & & & $\begin{array}{l}0.926^{*} \\
13.042 * *\end{array}$ \\
\hline I34 & & & & & & $\begin{array}{l}0.762^{*} \\
13.997^{* *}\end{array}$ \\
\hline I35 & & & & & & $\begin{array}{l}0.764 * \\
18.092 * *\end{array}$ \\
\hline
\end{tabular}

Note. $*$ Standardized loading; $* *$ t-value; $* * *$ Composite Reliability $* * * *$ Average variance extracted

\section{Discussion}

Hypothesis testing was done to check the structural model linear relationships between independent and dependent variables using regression analysis by calculating standardized beta estimates with the help of 
t-statistics. For hypothesis $\mathrm{H} 1$, the $\beta=0.47, \mathrm{t}=8.4, \mathrm{p}=0.01$, which indicates that product information (PI) accessed via QR codes had significant influence on perceived usefulness (PUM), Shin et al., (2012) also found similar result where quality of product information accessed via QR codes had positive effect on perceived usefulness (PU). Hypothesis $\mathrm{H} 2$, the $\beta=0.61, \mathrm{t}=10.6, \mathrm{p}=0.01$, indicates that advertisement (AD) accessed via QR codes had significant influence on perceived usefulness (PUM), in contrast Narang et al (2012) had found that advertisements involving QR code do not influence consumer attitude, but Jung, et al. (2012) found that advertisement $\mathrm{QR}$ codes influence intention to use. Hypothesis $H 3$, the $\beta=0.14, \mathrm{t}=5.2, \mathrm{p}=0.01$, indicates that sales promotion (SP) accessed via QR codes had significant influence on perceived usefulness (PUM), Singh and Bamoriya (2013) had found that different sales promotion incentives like discount coupons, loyalty points, free downloads, sweepstakes were given different weightages by respondents in usage of QR codes. Hypothesis H4, the $\beta=0.21, \mathrm{t}=9.1, \mathrm{p}=0.01$, indicates that billing and payment (BP) accessed via $\mathrm{QR}$ codes had significant influence on perceived usefulness (PUM), similar argument was proved by (Lubua \& Pretorius, 2018; Elue \& Nakakawa, 2018) but adversely Cabanillas et al., (2015) in their study found negative relationship of security with attitude to use $\mathrm{QR}$ codes. $\mathrm{H} 5$, the $\beta=0.58, \mathrm{t}=13.9, \mathrm{p}=0.01, \mathrm{QR}$ codes for marketing purposes with perceived usefulness(PUM) had significant influence on intention to use(IUM) among users, Cabanillas et al. (2015) had similar results.

\subsection{Implications and Conclusions}

Markets which are overcrowded by customers segments, competitors, large number of internet and smart phone users, distressed customers who frequently shop for daily needs, people with busy work culture are perfect market ingredients of QR code implementation in marketing activities. Africa with a total of 453 million internet users makes a good case for use of QR codes in marketing and sales (SCANOVA, 2019). On technological front when majority of consumers are smart phone users, QR code generation costs less and its usage is easy and fast which makes it feasible to implement.

In Africa $80 \%$ of the population had mobile phones, at the end of 2015 only $20 \%$ of them used internet in their mobile phone (Scitechafrica, 2019) this was low but certainly there is great opportunity in the future course of time that mobile phone internet users will rise. Mastercard, Standard bank, Nedbank, First National Bank, Associated Media Publishing, Star FM Zimbabwe are some examples which successfully applied QR codes but there are very little know marketing usage of QR codes. In other global geographical locations like South Korea, "Tesco Homeplus" created successful idea of virtual store with QR codes to help customers to shop while travelling and received door delivery. Tesco took clear competitive advantage using QR codes over other competitors. Asare and Asare (2015) in their study had discussed companies successfully using QR codes for marketing activities. The present study drove in the same path proving QR code application in marketing activities are perceived useful and well accepted by respondents. Lombardi et al. (2017) in their study found mixed results for QR code acceptance by customers.

In the present study, testing of items and subsequently elimination of some, refined the list with factors emerging via product information(PI), advertising(AD), sales promotion(SP) and billing \& payments(BP) considered to be most practiced activities of marketing for adopting and using $\mathrm{QR}$ codes. Hence practicing managers can focus on PI,AD,SP and BP activities for implementing QR codes for their marketing activities. The relation between $\mathrm{PI}, \mathrm{AD}$,SP and BP activities were not well established in the past from QR codes point of view, but evidence shows certain acceptable amount of relationship was established which concludes that these four activities can go in one basket. All the five hypotheses (PI-PUM; AD-PUM; SP-PUM; BP-PUM; PUM-IUM) were accepted. The relationship is evident between PI,AD,SP and BP activities and usefulness as perceived by the respondents, further they also had reported intention to use the QR codes for these activities. Several studies as (Okazaki et al., 2011; Ann, 2012; Lubua \& Pretorius, 2018) had indicated that consumer attitude is favorable towards usage of QR codes for marketing activities.

Though PI,AD,SP and BP activities are related to marketing, they are heterogeneous in nature like each activity is independent by practice. Reliability of QR codes implementation in these four activities was necessary and their acceptance was further tested, which paved way to indicate that respondent's acceptance had high correlation for such implementation with perceived usefulness and intention to use the QR codes in the future. Importantly to be considered are respondent's opinion about perceived usefulness and expression on intention to use QR codes in future course of time.

\subsection{Limitations and Future Directions}

The important limitation; this study considered sample respondents from four nations, reasons for this are financial and manpower constraints. This study was not sponsored by any research project, hence personal funds 
were used. The first reason for selecting four countries for data collection is, they are ranked in top 10 populous nations of Africa; Nigeria ranks 1, Egypt ranks 3, South Africa ranks 6 and Sudan ranks 10, also they are fastest smartphone and internet growing markets linking to growth of QR code use, discussed in the introduction section. The second reason for selecting these countries is convenience of data collection sources.

To address this limitation greater number of countries can be considered in future studies. In order to study sample respondents from more nations, attaining a research project sponsorship would be a viable option to cover the costs to be incurred in vast data collection.

Present study focused on whether product information, advertisements, sales promotion and billing/ payment accessed through QR codes had perceived usefulness and future intention to use. There is plethora of important constructs in technological theories/model TRA, TAM 1, $2 \& 3$ and UTAUT $1 \& 2$ which can be adapted for further studies. Constructs such as self-efficacy, social influence, subjective norm, expectancy, hedonic motivations can be considered for further studies to extend QR codes literature.

This study did not give opportunity to look beyond QR codes, so respondent's opinion might have been biased. It would give more insights if a comparative study is done between product information, advertisements, sales promotion and billing/ payment accessed through QR codes and through traditional media like television, newspapers, bill boards, magazines, radio. This comparison study may help practicing managers to optimize their marketing budgets.

Future studies can also establish priori variables such as relevance, appeal, attractiveness and security to investigate whether they influence product information, advertising, sales promotion and billing \& payment respectively, directions can be drawn for decision makers to consider influence of the relationship when considering QR codes adoption for marketing.

\section{Acknowledgments}

I thank African collegues and students for cooperating in collecting data for this study. I would also appreciate collegues who spared their valuable time on item finalization.

\section{References}

Ajzen, I. (1991). The Theory of Planned Behavior. Organizational Behavior and Human Decision Processes, 50, 179-211. https://doi.org/10.1016/0749-5978(91)90020-T

Ajzen, I., \& Fishbein, M. (1980). Understanding attitudes and predicting social behavior. Englewood Cliffs, NJ: Prentice-Hall.

Ann, H. (2012). Cracking the Mobile Code. Entrepreneur, 56-57.

Asare, I. T., \& Asare, D. (2015). The Effective Use of Quick Response (QR) Code as a Marketing Tool. International Journal of Education and Social Science, 2(12), 67-73.

Cabanillas, F. L., Luna, I. R., \& Rios, F. J. M. (2015). User behaviour in QR mobile payment system: the QR Payment Acceptance Model. Technology Analysis \& Strategic Management, 27(9), 1031-1049. https://doi.org/10.1080/09537325.2015.1047757

Chong, J. H. (2017). The factors motivating consumers to accept quick response code as a new form of organisation marketing tool: a structural modelling approach. International Journal of Modelling in Operations Management, 6(3), 153-171. https://doi.org/10.1504/IJMOM.2017.084796

Cronbach, L. J. (1971). Test validation. In R. L. Thorndike (Ed.), Educational measurement (2nd ed.). Washington, D.C.: American Council on Education.

Davis, F. D. (1989). Perceived Usefulness, Perceived Ease of Use, and User Acceptance of Information Technology. MIS Quarterly, 13(3), 319-340. https://doi.org/10.2307/249008

Elue, S., \& Nakakawa, A. (2018). Framework Towards Enhancing Adoption of Electronic Payment in A Developing Economy: A Case of Uganda. The African Journal of Information Systems, 10(3), 222-245. Retrieved from https://digitalcommons.kennesaw.edu/ajis/vol10/iss $3 / 5$

Fornell, C. G., \& Larcker, D. F. (1981). Evaluating structural equation models with unobservable variables and measurement error. Journal of Marketing Research, 18(1), 39-50. https://doi.org/10.1177/002224378101800104

Geraldine, G. (2017). Masterpass QR Now Live in 7 Markets in Middle East and Africa Powering the development of digital ecosystems, Masterpass QR. 
Gonul, F., Qiu, C., \& Zhou, E. (2016). Whether or not to use a quick response code in the ad. International Journal of Electronic Marketing and Retailing, 7(1), 22-38. http://dx.doi.org/10.2139/ssrn.2487939

Hair, J. F., Black, W. C., Babin, B. J., \& Anderson, R. E. (2009). Multivariate Data Analysis (7th ed.). Pearson New International Edition.

Hair, J. F., Marko, S., Lucas, H., \& Volker, K. (2014). Partial Least Squares Structural Equation Modeling (PLS-SEM): An Emerging Tool for Business Research. European Business Review, 26, 106-121.

Higgins, L. M., Wolf, M. M., \& Wolf, M. J. (2014). Technological change in the wine market? The role of QR codes and wine apps in consumer wine purchases. Wine Economics and Policy, 3, 19-27. https://doi.org/10.1016/j.wep.2014.01.002

Hinkin, T. R. (1995). A Review of Scale Development Practices in the Study of Organizations. Journal of Management, 21(5), 967-988. https://doi.org/10.1016/0149-2063(95)90050-0

Humbani, M., \& Wiese, M. (2018). A Cashless Society for All: Determining Consumers' Readiness to Adopt Mobile Payment Services. Journal of African Business, 19(3), 409-429. https://doi.org/10.1080/15228916.2017.1396792

Kim, E. Y., \& Yoon, N. (2014). Perceived QR code technological attributes in the smart shopping context. Journal of Global Fashion Marketing, 5(4), 297-307. https://doi.org/10.1080/20932685.2014.926130

Lavidge, R. J., \& Steiner, G. A. (1961). A Model for Predictive Measurements of Advertising Effectiveness. Journal of Marketing, 25(6), 59-62. https://doi.org/10.2307/1248516

Liebenberg, J., Benade, T., \& Ellis, S. (2018). Acceptance of ICT: Applicability of the Unified Theory of Acceptance and Use of Technology (UTAUT) to South African Students. The African Journal of Information Systems, 10(3), 160-173. $\quad$ Retrieved from https://digitalcommons.kennesaw.edu/ajis/vol10/iss3/1

Lombardi, A., Carfora, V., Cicia, G., Giudice, T.D., Lombardi, P., \& Panico, T. (2017). Exploring Willingness to Pay for QR Code Labeled ExtraVirgin Olive Oil: An Application of the Theory of Planned Behavior. Int. J. Food System Dynamics, 8(1), 14-31. https://doi.org/10.18461/ijfsd.v8i1.812

Lubua, E. W., \& Pretorius, P. (2018). The role of the transaction assurance, perceived cost and the perceived innovation in the decision to continue using mobile money services among small business owners. The African Journal of Information Systems, 10(2), 120-138. Retrieved from https://digitalcommons.kennesaw.edu/ajis/vol10/iss2/3

Mobi thinking. (2012). The insider's guide to mobile Web and marketing in Nigeria. Retrieved from https://mobiforge.com/news-comment/the-insiders-guide-to-mobile-web-and-marketing-nigeria

Narang, S., Jain, V., \& Roy, S. (2012). Effect of QR Codes on Consumer Attitudes. International Journal of Mobile Marketing, 7(2), 52-64. https://doi.org/10.1177/1847979018812323

Okazaki, S., Angeles, N., Prokriti, M., \& Kirk, P. (2017). The curious versus the overwhelmed: Factors influencing QR codes scan Intention. Journal of Business Research, 99, 498-506. https://doi.org/10.1016/j.jbusres.2017.09.034

Okazaki, S., Hirose, M., \& Li, H. (2011). QR Code Mobile Promotion: An Initial Inquiry. In S. Okazaki (Ed.), Advances in Advertising Research (Vol. 2, pp. 405-420).

Podsakoff, P. M., MacKenzie, S. B., Lee, J.-Y., \& Podsakoff, N. P. (2003). Common method biases in behavioral research: A critical review of the literature and recommended remedies. Journal of Applied Psychology, 88(5), 879-903. https://doi.org/10.1037/0021-9010.88.5.879

Ramayah, T., Cheah, J., Chuah, F., Ting, H., \& Memon, M. A. (2016). Partial Least Squares Structural Equation Modeling (PLS-SEM) using SmartPLS 3.0, An Updated and Practical Guide to Statistical Analysis.

Rao, M. (2012). Mobile Africa Report 2012 - Sustainable Innovation Ecosystems. Retrieved from http://ictet.org/downloads/Mob_i3MuC0_zkwI.pdf

Retrieved

from https://newsroom.mastercard.com/press-releases/masterpass-qr-now-live-in-7-markets-in-middle-east-and-a frica/

Robert, P. A., \& Yeolib, K. (2013). On the relationship between coefficient alpha and composite reliability. Journal of Applied Psychology, 98(1), 194-198. https://doi.org/10.1037/a0030767 
SCANOVA. (2019). QR Codes in Africa: Common Use Cases Across Various Industries. Retrieved from https://scanova.io/blog/qr-codes-in-africa/\#utmsource=yt_pr_qr-code-statistics_bod\&utm_medium $=$ blog\&utm_campaign $=$ content

Scitechafrica. (2019). Why QR Code \& Mobile Payment Technology is Africa's Next Big Move. Retrieved from https://scitechafrica.com/2017/09/21/why-qr-code-mobile-payment-technology-is-africas-next-big-move/

Shin, D. H., Jung, J., \& Chang, B. H. (2012). The psychology behind QR codes: User experience perspective. Computers in Human Behavior, 28, 1417-1426. https://doi.org/10.1016/j.chb.2012.03.004

Singh, R., \& Bamoriya, H. (2013). QR Codes in Print Advertising: Elucidating Indian Vogue Using Content Analysis. Management \& Marketing, 8(2), 353-368. https://ssrn.com/abstract=2331288

Venkatesh, V., \& Bala, H. (2008). Technology Acceptance Model 3 and a Research Agenda on Interventions. Decision Sciences, 39(2), 273-315. https://doi.org/10.1111/j.1540-5915.2008.00192.x

Venkatesh, V., \& Davis, F. (1996). A Model of the Antecedents of Perceived Ease of Use: Development and Test. Decision Sciences, 27(3), 451-481. https://doi.org/10.1111/j.1540-5915.1996.tb00860.x

Venkatesh, V., \& Davis, F. (2000). A Theoretical Extension of the Technology Acceptance Model: Four

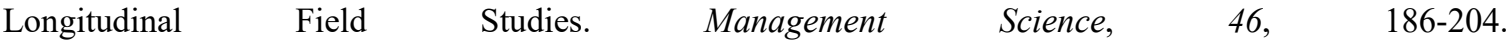
https://doi.org/10.1287/mnsc.46.2.186.11926

Venkatesh, V., Morris, M., Davis, G., \& Davis, F. (2003). User Acceptance of Information Technology: Toward a Unified View. MIS Quarterly, 27, 425-478. https://doi.org/10.2307/30036540

Venkatesh, V., Thong, J. Y. L., \& Xu, X. (2012). Consumer Acceptance and Use of Information Technology: Extending the Unified Theory of Acceptance and Use of Technology. MIS Quarterly, 36, 157-178. https://doi.org/10.2307/41410412

Verma, J. (2013). Data Analysis in Management with SPSS. Springer India 2013.

\section{Appendix A}

\section{Questionnaire items}

\begin{tabular}{|c|c|c|}
\hline Items(I) & $\begin{array}{l}\text { Adapted and modified } \\
\text { from }\end{array}$ & $\begin{array}{l}\text { Expert comment for } \\
\text { deleted items }\end{array}$ \\
\hline \multicolumn{3}{|l|}{ I1:QR codes used are able to lead to proper website content } \\
\hline \multicolumn{3}{|l|}{ I2:Currency of information accessed through $\mathrm{QR}$ codes is very high } \\
\hline \multicolumn{3}{|l|}{ I3:Width and depth of information accessed through QR codes is satisfactory } \\
\hline \multirow{2}{*}{\multicolumn{3}{|c|}{ I5:Information accessed through QR codes is sufficient for buying decision }} \\
\hline & & \\
\hline \multicolumn{3}{|l|}{ I6:Used QR code to access the whole advertisement content } \\
\hline \multicolumn{3}{|l|}{ I7:QR codes were useful in accessing most suitable product information } \\
\hline \multicolumn{3}{|l|}{ I8:Advertisements accessed through QR code were attractive } \\
\hline \multicolumn{3}{|l|}{ I9:Advertisements accessed through $Q R$ code were of great value } \\
\hline \multicolumn{3}{|l|}{ I10:Message in the advertisements viewed through QR code had impacted } \\
\hline \multicolumn{3}{|c|}{$\begin{array}{l}\text { I11:The presentation of advertisement accessed through QR code is highly } \\
\text { creative } \\
\text { Narang, Jain }\end{array}$} \\
\hline \multirow{2}{*}{$\begin{array}{l}\text { I12:Information presented in the advertisement accessed through } Q R \text { code is } \\
\text { relevant to needs. }\end{array}$} & 2012; Singh and Bamoriya, & \\
\hline & 2013; Okazaki et al., 2011 & \\
\hline \multicolumn{2}{|l|}{ I13:Advertisements accessed through $Q R$ code was appealing } & Redundant \\
\hline \multicolumn{3}{|l|}{ I14:Many advertising QR codes at one place are useful } \\
\hline \multicolumn{3}{|l|}{ I15:Advertisements accessed through $Q R$ codes were very creative and sales } \\
\hline \multicolumn{3}{|l|}{ promotion found through them were useful } \\
\hline \multicolumn{3}{|l|}{ I16:Sales promotions offered through $Q R$ codes were exiting } \\
\hline \multicolumn{3}{|l|}{ I17:Sales promotional QR codes had motivated in buying } \\
\hline I18:Sales promotional $\mathrm{QR}$ codes at times influenced to change buying decision & Singh and Bamoriya, 2013 & \\
\hline \multirow{2}{*}{\multicolumn{3}{|c|}{$\begin{array}{l}\text { I19:Price discounts and coupons were found commonly through QR promotion } \\
\text { codes }\end{array}$}} \\
\hline & & \\
\hline I20:Would like to use more and more QR codes for accessing sales pr & & \\
\hline
\end{tabular}




\section{offers.}

I21:Sales promotion found through QR code was beneficial

I22:QR codes gave easy access to bill.

I23:QR codes used for accessing the bill had accurate monetary information

\section{I24:Bill accessed through $Q R$ code was very transparent}

I25:Bill accessed through QR code had all the details related to sale transaction

I26:Payment of bills through QR codes is easy and fast.

Cabanillas, Luna and Rios, 2015; Kim and Yoon, 2014, Lubua, and

Confusing

Pretorius, 2018

I27:Felt minimized risk paying through $Q R$ codes

I28:QR codes are compatible to customers use

I29:QR codes are beneficial to customers

I30:QR codes are very useful in end to end purchase activities

I31: $Q R$ codes are valuable to customers

I32:Assuming I had access to QR codes, I intend to use them.

Redundant

I33:I will use QR codes in all my future purchases

I34: Given that I had access to QR codes, I predict that I would use them.

I35: I plan to use QR codes in my next purchase.

\section{Copyrights}

Copyright for this article is retained by the author(s), with first publication rights granted to the journal.

This is an open-access article distributed under the terms and conditions of the Creative Commons Attribution license (http://creativecommons.org/licenses/by/4.0/). 